Sādhanā, Vol. 18, Part 1, March 1993, pp. 57-75. (C) Printed in India.

\title{
Gasifier-based power generation: Technology and economics
}

\author{
B N BALIGA, S DASAPPA, U SHRINIVASA and H S MUKUNDA \\ Centre for the Application of Science \& Technology to Rural Areas, Indian \\ Institute of Science, Bangalore 560012, India
}

\begin{abstract}
The paper describes a $100 \mathrm{~kW}$ power generation system installed at Port Blair, Andaman and Nicobar Islands, under a project sponsored by the Department of Non-Conventional Energy Sources, Government of India. The system consists of a wood gasifier utilising the waste wood from a saw mill and a diesel engine genset. The performance of the total system and its elements are presented along with economics of operation. To bring out the economics of using such renewable energy devices for power generation, some realistic situations are considered for which the effective cost of power and the pay-back period for the investment are evaluated. The economics is compared with that of a similar system of $3.7 \mathrm{~kW}$ capacity.
\end{abstract}

Keywords. Power generation; wood gasifier; renewable energy.

\section{Introduction}

Wood gasifier-based power generation could be considered a technology based on a renewable resource when it is used with captive biomass production. The method results in saving of diesel oil to the extent of 60 to $80 \%$ of the normal consumption of diesel-based generation, by substitution of the fossil fuel with the gas generated from biomass, and hence, such power generation is being encouraged in several countries over the last two decades.

Much of the work on large capacity gasifiers was carried out during the Second World War (see SERI 1979) using charcoal rather than wood. Though wood gasifiers have been built in later years (Walawender et al 1985, pp. 911-22), they were basically designed for thermal application and very little is known about their performance. There is a mention of some wood gasifiers in use in Indonesia (Kardona 1988), but their performance has not been reported. In recent times, Imbert gasifier systems of capacities varying from $50-500 \mathrm{~kW}$ (Zerbin 1984) have been installed in different countries. It has been reported that two gasifier engine systems of 60 and $125 \mathrm{~kW}$ have run together for approximately 12,000 hours in Guyana and further plans are ahead for a total capacity of $4.8 \mathrm{MW}$ to be located in a saw mill. The investment costs of Imbert power plants are said to be DM 3000-4000 (US $\$ 900-1100$ ) per $\mathrm{kW}$ of power output (Zerbin 1984).

For a technology to be commercially viable, its financial benefits should be meaningful, irrespective of whether saving in fossil fuel occurs or not. This is because saving 
of fossil fuel is not rewarded in any additional way. Studies on the economics of gasifiers have been made by the IISc group (Mukunda et al 1986) as early as in 1986 for the $3.7 \mathrm{~kW}$ system and by Jain (1987) for gasifiers of various capacities. However, such studies conducted at one point in time are not necessarily valid much later except in terms of principles because costs of various components would change with time. It is in this perspective that two cases where gasifiers have been installed are considered in this study. The current situation is more favourable for renewable energy systems because of the increasing cost of petroleum fuels and because other cheaper sources of energy are not in sight.

This paper deals with the development of a gasifier system to deliver power for a utility taking into consideration the favourable and not-so-favourable features of the site. In the process, an attempt is made to demonstrate successfully that a renewable energy device can compete economically and reliably with other modes of power generation by examining the economics of the 100 and the $3.7 \mathrm{~kW}$ gasifier systems.

Beginning with a description of the system and its performance, the component costs and the economic calculations are presented. Conclusions regarding the cost of installation, cost of power generation and the pay-back period are drawn. The corresponding results for the $3.7 \mathrm{~kW}$ system are also presented towards the end.

\section{The system elements}

The choice of the various components was dictated by the specific site conditions and requirements stated below.

- The Andaman and Nicobar (A \& N) electricity board requires about $60-70 \mathrm{~kW}$ of power round the clock for the utilities of the Chattam power house.

- Waste wood is available in plenty as the Chattam saw mill is located next door. The pieces are $100-150 \mathrm{~mm}$ cubes or slightly oblong pieces.

- The power house is located on the sea shore and hence sea water is available for cooling.

- The use of unskilled, semi-skilled and skilled labour as well as of supervisory personnel is to be minimised.

The foregoing factors imply the following features in the system design.

- The capacity of the system should be about $100 \mathrm{kWe}$.

- A facility to prepare wood chips of 40-60 mm size from the sidelings of $100-150 \mathrm{~mm}$, i.e. each of the pieces should be split into 8-12 chips.

- Advantage may be taken of the availability of sea water to design a simple cooling system.

- A conveyor to feed wood chips to the hopper, with provision for automation.

- A control system with data acquiring, logging and interactive monitoring capabilities for supervising the operations of the gasifier and engine-genset.

- Sensors for diesel flow rate, voltage, current, frequency and positions of motorised valves for regulation and monitoring the performance of the system.

We shall now examine the various elements in some detail.

\subsection{The reactor}

The reactor design for the $100 \mathrm{kWe}$ throatless gasifier is based on the same principles as that of the $5 \mathrm{~kW}$ gasifier developed by the present authors (Dasappa et al 1989). 
The reactor, as shown in figure 1, is double-walled, with the annular space being used to take out the hot gases. The inner diameter of the reactor is $350 \mathrm{~mm}$. The nominal flow of air at $100 \mathrm{kWe}$ output is about $40 \mathrm{~g} / \mathrm{s}$. The inducted air is shared between the top region and the six air nozzles located about $2.65 \mathrm{~m}$ from the top of the reactor in the ratio 40:60. The air taken in from the top helps in the oxidative pyrolysis of the wood pieces in contact with the wall which is kept hot by heat transfer from the hot gases moving up in the annular space. The superficial mass flux of the air flowing through the reactor from the top region is $0.25 \mathrm{~kg} / \mathrm{m}^{2} \mathrm{~s}$. The corresponding value for the $3.7 \mathrm{~kW}$ system is $0.12 \mathrm{~kg} / \mathrm{m}^{2} \mathrm{~s}$. This means that the $100 \mathrm{~kW}$ system is more compact. This is as expected because in the smaller reactor reduction in diameter is prevented by the need to account for the size of the wood chips. The velocity of the gas at the end of the conical region is maintained around $4 \mathrm{~m} / \mathrm{s}$ at a nominal gas generation rate of $60 \mathrm{~g} / \mathrm{s}$ to move any ash on the grate to the ash pit. The heating of the inner wall by the hot gases in the annular space helps in the easy movement of the wood chips and the conversion of the wood into char before it reaches the nozzle area. This is the criterion for the selection of the height above the air nozzle. The distance between the air nozzle and the grate is chosen to allow a residence time for residual tar oxidation and conversion of $\mathrm{CO}_{2}$ and $\mathrm{H}_{2} \mathrm{O}$ to $\mathrm{CO}$ and $\mathrm{H}_{2}$ through reactions with the char. The residence time of the chips in the reactor is of the order of $1.5-2.5 \mathrm{~h}$ depending on the gas flow while the char residence time is approximately 30 minutes

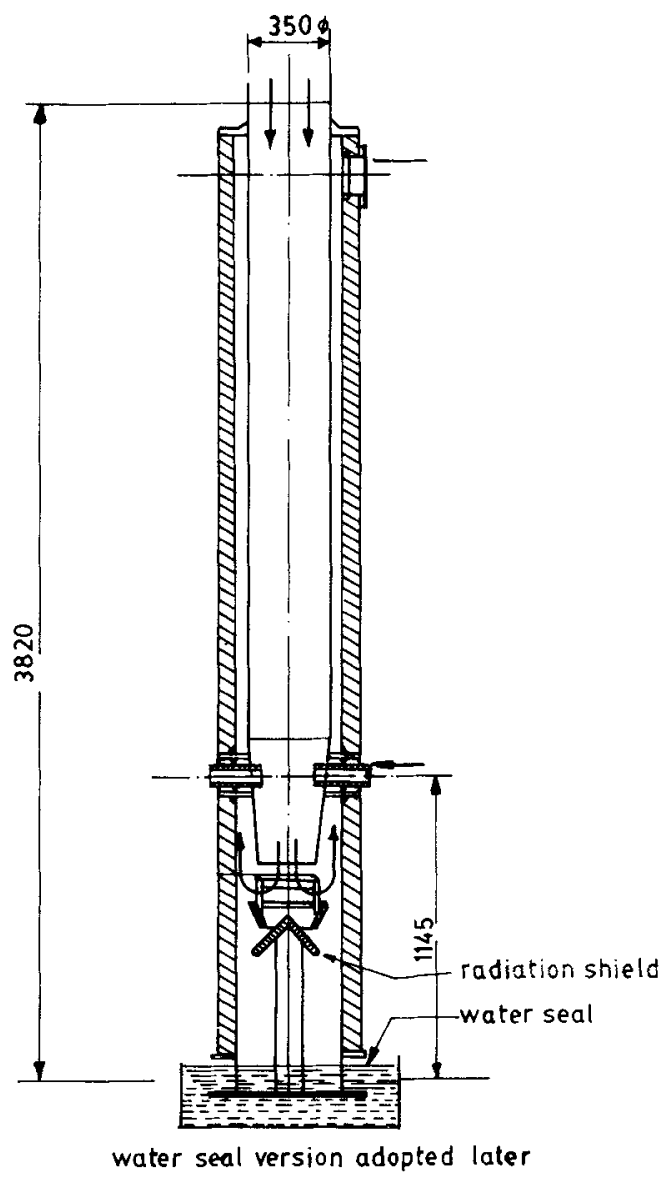

Figure 1. Reactor for the $100 \mathrm{~kW}$ gasifier system. (All dimensions in millimetres in this and all other figures.) 
below the air nozzles. These values of residence time ensure that the pyrolysis, oxidation and reduction reactions can occur adequately. Development of the reactor geometry was performed over a period of time. The problems encountered during the early period and their resolution are presented in appendix A. The basic reactor design remained the same as in the first prototype, except that a water seal was introduced at the bottom and the weld procedure was modified at the air nozzle area to eliminate thermal fatigue. The water seal at the bottom not only ensured a positive seal eliminating the cumbersome bottom cap but also made continuous ash disposal possible. However, introduction of a water seal required that the radiation flux (about $25 \mathrm{~kW} / \mathrm{m}^{2}$ ), from beneath the grate, be prevented from reaching the water surface. Therefore, a radiation shield whose design was based on the experience on the smaller system was adopted (Dasappa et al 1989). The shield is an integral part of the grate with provisions for easy discharge of the ash into the water seal. The final geometry is shown in figure 1; it differs from figure A1 (see appendix A) and has the bottom cap eliminated in favour of the water seal.

\subsection{The cooling system}

The hot combustible gases leaving the reactor are at a temperature of $550-750 \mathrm{~K}$ and carry dust and possibly tiny amounts of tar. The gases need to be cooled and

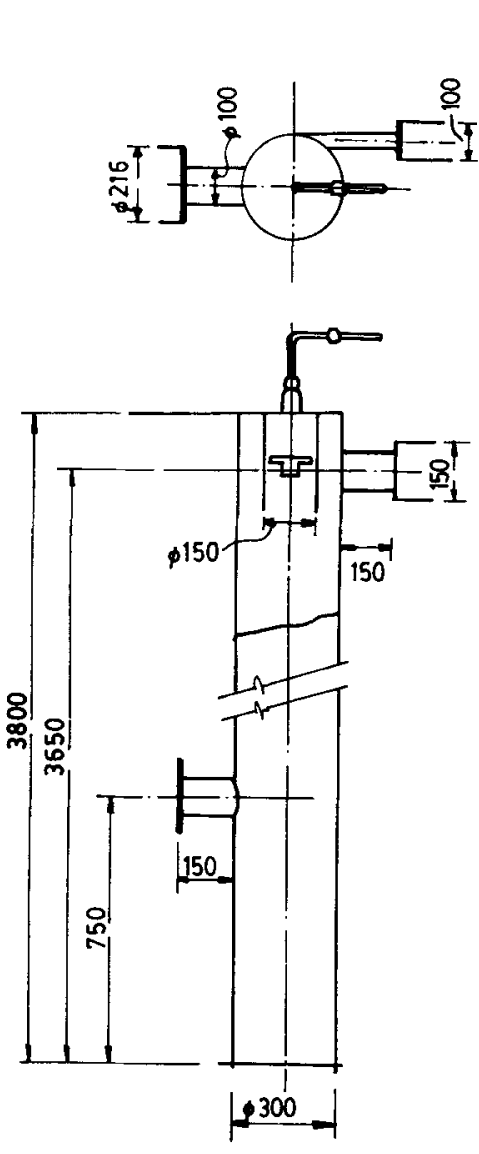

cooler-1

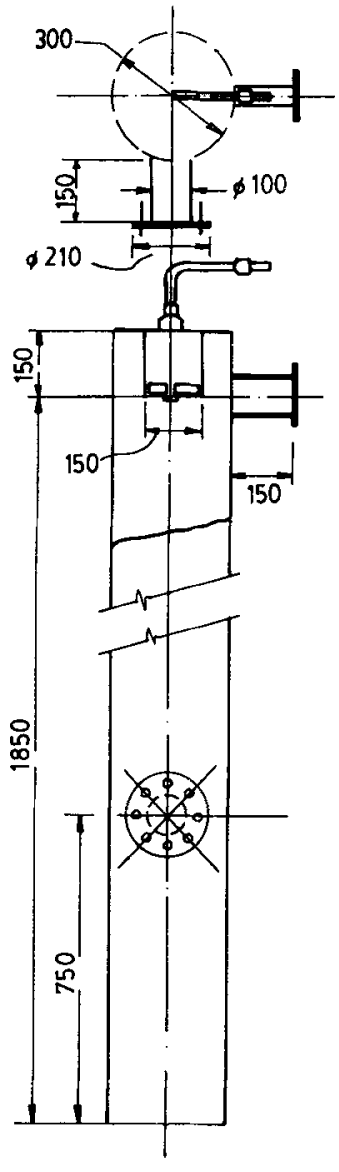

cooler -2
Figure 2. Details of the two coolers. 
cleaned before being allowed to enter the engine. Two coolers, each having a swirl sprayer (figure 2) were adopted. Flow to both the coolers comes from a special pump which can handle sea water. The cooling water, apart from removing the heat, also scrubs the gas and reduces the particulates. About $1 \mathrm{~kg} / \mathrm{s}$ of water flows through the system to cool the gas to near ambient conditions. Since water seals are required both for the gasifier and the cooling system, a common seal in the form of a pit was planned in this case. The pit also facilitates easy grate removal and emptying of the gasifier for maintenance.

\subsection{The cleaning system}

From the experience gained on the first prototype, it was clear that gases would still contain about $100 \mathrm{ppm}$ of dust and moisture at the end of the cooling and cleaning system. Therefore, a positive filtering system was necessary. From the cooler, the gas was led directly into a suitably designed cyclone, to eliminate water droplets and any dust. Various methods of filtering were considered before using a packed bed for the purpose. It is known that packed bed filters could be used for removal of submicron particles. The separation of dust in a bed is due to gravity settling, diffusional deposition, inertial deposition and flow interception. For the above factors to dominate, it is essential to have very low gas velocities and a bed with a tortuous passage and an affordable pressure drop. Thus a sand bed (particle size 250-600 microns) of $0.1 \mathrm{~m}$ thickness was chosen. Apart from its capability to retain fine solid particles the bed could also separate any fine mist present in the gas. The pressure drop characteristics of the bed, both under wet and dry conditions, were evaluated in small-scale experiments and a design was arrived at to handle about $60 \mathrm{~g} / \mathrm{s}$ of gas. The pressure drop across the packed bed was around $0.5 \mathrm{kPa}$ in the dry condition and $1.0 \mathrm{kPa}$ in the wet condition at $60 \mathrm{~g} / \mathrm{s}$ flow rate.

After the filter, the gas would be still saturated with moisture, and be warmer than the ambient by a few degrees; the moisture could condense elsewhere in the pipeline. Therefore, a mist eliminator was designed using coir pith as the bed medium. Coir pith can hold moisture up to $200 \%$ of its own weight and is found to have high resistance to biodegradation. Figure 3 shows the filtering unit. A separate water seal at the bottom helps in easy maintenance of the system. The bed material is held in a structure supported with mesh, with easy assembly and removal facility. The gas first passes through the sand bed and then through the coir bed.

\subsection{The wood processing system}

Considerable thought was given to the choice of technique for size reduction of wood. The requirements were to reduce from an average of $100-150 \mathrm{~mm}$ to $40-60 \mathrm{~mm}$ at a rate of $200-300 \mathrm{~kg} / \mathrm{h}$. This capacity was arrived at as follows. The average consumption of wood is $1 \mathrm{~kg} / \mathrm{kWh}$. At an average of $60 \mathrm{~kW}$ load for a 10 -hour period the wood consumption would be $600 \mathrm{~kg}$. It was thought that it would be satisfactory if this amount of wood chips was generated in about 2-3 hours. No machine specifically suited to the requirements of the site was available in the market. The machines from overseas were generally of much higher capacity $-1000 \mathrm{~kg} / \mathrm{h}$ upwards. Hence, a design which could adapt an existing machine, such as a power press, was thought of. A 20-ton hydraulically operated power press was obtained and was fitted with a cutting tool made of heat-treated spring steel. The electric motor in this system was of $3.7 \mathrm{~kW}$ 

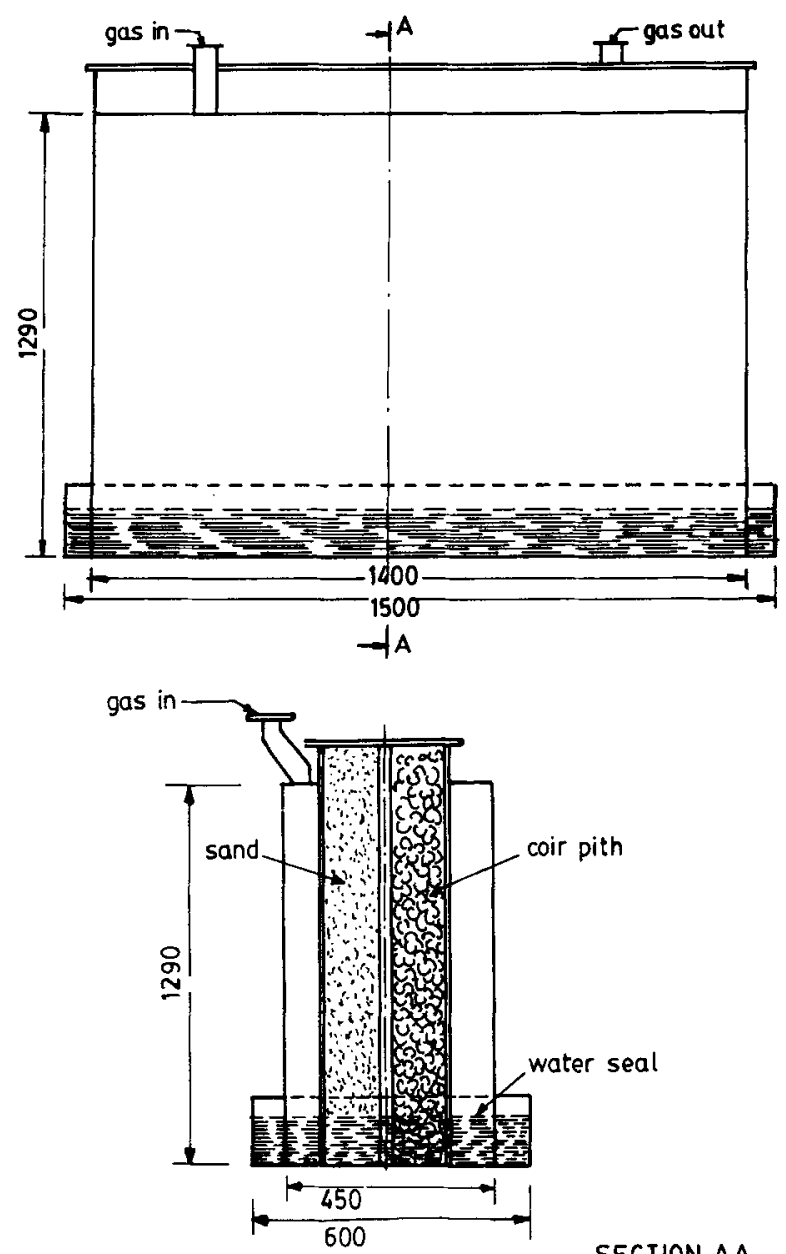

SECTION AA

Figure 3. Structure of the filter unit.

rating. Tests using blocks of the same form and size as at the site showed that about $100 \mathrm{~kg} / \mathrm{h}$ of wood could be processed with some initial training on the operational procedure. This was considered satisfactory as it was found from tests in the early period that the average wood consumption is about $50 \mathrm{~kg} / \mathrm{h}$ for the lighting load profile of the saw mill.

\subsection{The wood-chip conveyor}

A belt-type conveyor with a wood dump of about 1 ton is used to convey the chips into the hopper. The belt is of a special material with buttons to prevent wood chips from slipping back into the dump. The conveyor is about $12 \mathrm{~m}$ long and $5 \mathrm{~m}$ high. The belt is driven by a $1.5 \mathrm{~kW}$ motor with a gear reduction unit.

A complete layout of the system is shown in figure 4 .

\subsection{Performance of the system}

The performance of the gasifier engine-genset system is considered in (a) manual mode and (b) auto mode. 


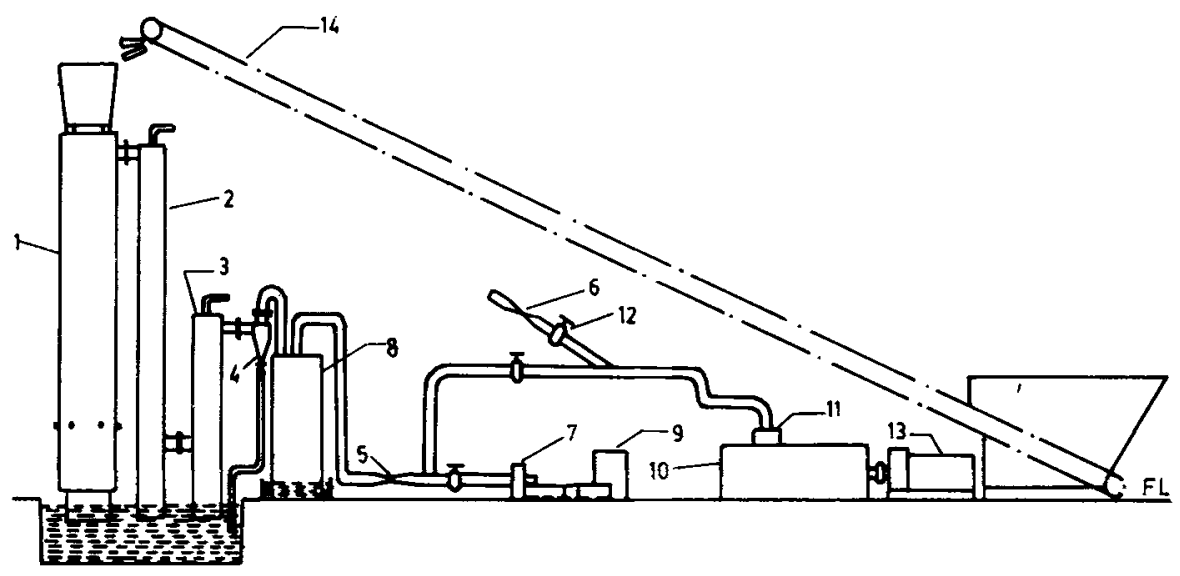

Figure 4. Complete lay out of the system (1: the reactor; 2: first cooler; 3: second cooler; 4: cyclone separator; 5 : venturi for gas flow; 6 : venturi for air flow; 7: blower; 8: filter; 9: burner; 10: engine; 11: the manifold; 12: air valve; 13: alternator; and 14: fuel loading system).

The specifications of the naturally aspirated diesel engine are given below.

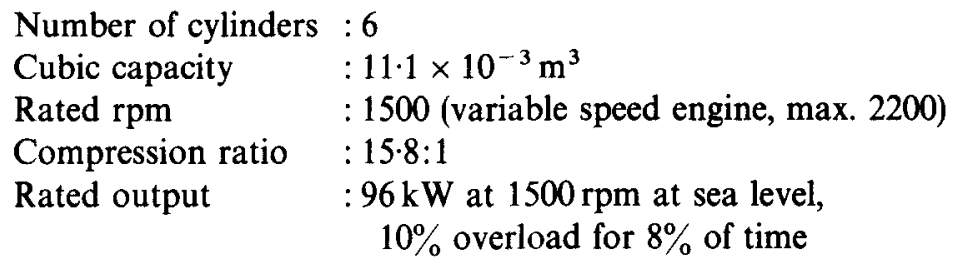

The engine is coupled to a $110 \mathrm{kVA}$ alternator. The gas and air mixture is led to the engine inlet using an auxiliary air manifold. The oil bath air filters on the diesel engine were retained to act as security filters for the gas and air mixture during the dual-fuel operation.

The engine was tested on the diesel mode to establish its performance by measuring the diesel consumption, load, air induction rate and the rpm. Figure 5 shows the results of the tests. The lowest values of specific fuel consumption (sfc) $-260 \mathrm{~g} / \mathrm{kWh}-$ are obtained at about $80 \%$ of the full load. The diesel flow rate varies from $1.47 \mathrm{~g} / \mathrm{s}$ $(5.3 \mathrm{~kg} / \mathrm{h})$ at no load to about $5.7 \mathrm{~g} / \mathrm{s}(20.5 \mathrm{~kg} / \mathrm{h})$ at full load. Venturi measurements indicate that the air inducted at no-load conditions is about $120 \mathrm{~g} / \mathrm{s}$. The induction efficiency is estimated at $79 \%$ at no load gradually reducing to $71 \%$ at full load. This is accompanied by $4 \%$ reduction in rpm on full load. The fall in induction efficiency may be related to the dynamic effects, valve events, cylinder pressure and compression pressure (Taylor \& Taylor 1961). Due to the altitude effect at Bangalore ( $920 \mathrm{~m}$ above sea level), there is a derating in the power output of the system to the extent of about $10 \%$. The overall efficiency of the engine-genset peaks to $35 \%$ at the low sfe region. The reduction in the overall efficiency at low loads is due to the frictional power loss which is estimated at $15 \mathrm{~kW}$ for this engine.

\subsection{Manual mode}

A number of experiments have been carried out and the following parameters were measured during the tests: Engine rpm, voltage, current, frequency, air flow rate, gas 


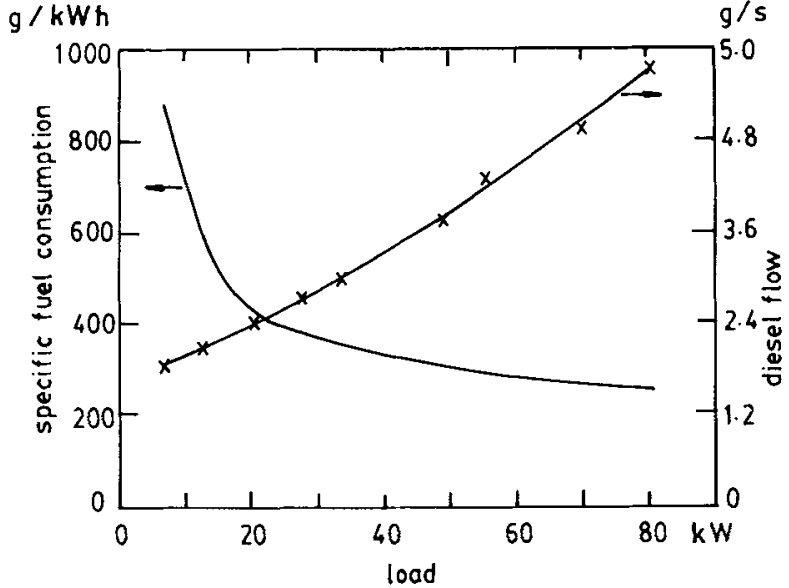

Figure 5. Specific fuel consumption $(\mathrm{g} / \mathrm{kWh})$, and diesel flow vs load in kilowatts.

flow rate, diesel flow rate, pressure drop across the elements of the gasifier system, wood consumption rate, gas composition, gas calorific value, dust and condensibles.

The system performance was evaluated with air-valve control, by leaving the governer linkage free and keeping the gas valve fully open. Changing of the resistance along the air line changed the gas-flow rate at any given load, and hence the diesel replacement. Figure 6 shows the results of a typical run where the variations of many parameters with load are presented. With increase in load beyond $70 \mathrm{~kW}$ the diesel replacement gradually reduces from $75 \%$ to about $50 \%$ at $80 \mathrm{~kW}$. This is because the available air-to-fuel ratio at full load is about 21.0 compared to 26 in smaller capacity engines like $3.7 \mathrm{~kW}$ in which a single point diesel replacement as high as $90 \%$ has been obtained (Dasappa et al 1989), i.e. this engine has been designed with much less excessair factor than the small capacity engines. The overall efficiency obtained in the dualfuel run is $21 \%$ at $75 \%$ diesel replacement. This constitutes a $36 \%$ reduction in the

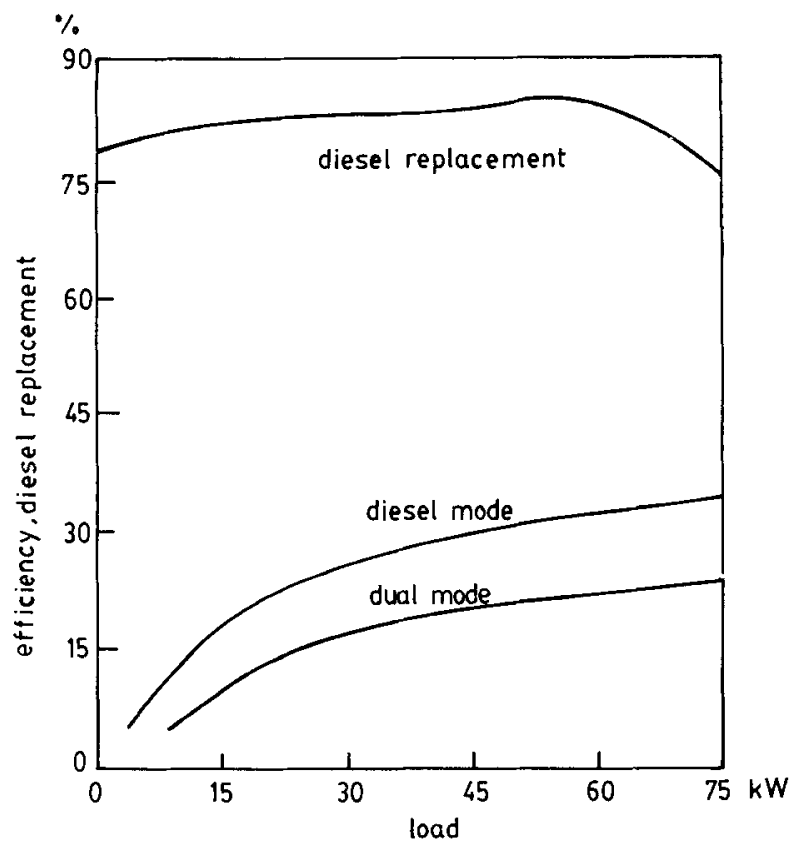

Figure 6. Efficiency and diesel replacement vs load. 
engine efficiency compared to a diesel-only case. The exhaust gas temperature of the engine in the dual-fuel mode is higher than in the diesel-alone mode by about 125 to $175 \mathrm{~K}$, because of incomplete combustion in the engine cylinder. The wood consumption rate is around $1 \mathrm{~kg} / \mathrm{kWh}$ at an average diesel replacement of $75 \%$. An on-line facility was created to measure the particulates and condensibles in the gas. This consists of a bypass line with a valve, a scoop to draw a part of the flow through the bypass line, a venturi, and two sets of cotton filters. The flow rejoins the main duct after passage through the filters. The cotton filters are weighed at the beginning and at the end of a set period of about an hour. The gain in weight of the filters constitutes the particulates, moisture and possibly tar. Further analysis is made as in Dasappa et al (1989). Particulate and condensible levels of 40-60 ppm are recorded at varying load conditions. Such reduced levels are possible because of the use of a positive filtering system. It is also noticed that after about 100 hours of operation, there is no trace of any carbon deposit either in the engine cylinder or on the valve seatings.

During these runs it was necessary to take into account the system response by suddenly loading the system or by suddenly throwing-off the load. It was found that load throw-off from $60 \mathrm{~kW}$ to no-load condition and loading upto $60 \mathrm{~kW}$ was handled by the engine governer, beyond which bursts of flame were noticed in the engine exhaust during load throw-off. In comparison, experience on spark-ignited engines (Zerbin 1984) with gas shows that they can handle such changes in steps of $15 \%$ of the rated load only. The fact that the engine is on dual-fuel with the governer left free has the advantage that it responds to varying load conditions sufficiently fast, thus making the system more user friendly. A butterfly valve which is easy to operate was incorporated for controlling the air flow. Based on the above runs, the parameters identified for monitoring to obtain the best diesel replacements are the diesel flow rate, rpm (frequency), load and air line resistance. It is also important to note that in a utility, the load throw-off and load changes on the engine genset occur without prior information to the power plant operator. Therefore, a control system is necessary for these routine operations.

\subsection{The control system}

For the proposed control system, it was necessary to obtain electrical signals of the governing parameters, like diesel flow rate, current, voltage, frequency etc. to actuate the air control valve for achieving the best possible diesel replacement under the prevalent circumstances. Since an exploration revealed that commercially available transducers for diesel flow are inadequate, development of a suitable transducer became inevitable. Specifications of the transducer were laid down from the experience gained in the manual mode operation as given below.

$\begin{array}{ll}\text { Diesel flow rate } & : 0.2-5 \mathrm{~g} / \mathrm{s} \\ \text { Voltage on the three phases } & : 400-450 \mathrm{~V} \\ \text { Current on the three phases } & : 0-140 \mathrm{~A} \\ \text { Frequency } & : 48-52 \mathrm{~Hz} \\ \text { Outputs } & : 0-10 \mathrm{mV}\end{array}$

Using these parameters the following transducers were developed (Rajan et al 1990).

As mentioned earlier, the diesel flow rates were about $1.4-5.7 \mathrm{~g} / \mathrm{s}$ in the diesel mode 
and would be in the range of $0.2-5.0 \mathrm{~g} / \mathrm{s}$ in the dual-fuel mode. A sensor with an output voltage signal of $0-10 \mathrm{mV}$ range was developed using hot-wire anemometry and Wheatstone circuit principles. The change in resistance across a wire due to the flow of diesel is converted to an output signal, the resistance of the wire being a function of the diesel flow rate. One of the disadvantages of this system is that calibration between the output and the diesel flow rate is nonlinear and this calls for the use of a microprocessor for the conversion of electrical output to flow rate data.

The voltage generated is converted into a signal by tapping the phase voltage and using a suitable circuit to obtain an output in $0-10 \mathrm{mV}$ range.

Nonavailability of current transformers to deliver a linear output voltage, especially at higher loads, resulted in development of a current transducer. This consists of a low resistance coil, the induced voltage across it being sensed as a function of the current flowing through it. The variation of the current is obtained as a function of the coil voltage which is linear over the entire range specified earlier.

The frequency is obtained as a function of the DC voltage from the frequency to voltage converter, which is linear in the range of useful frequencies.

Signals from the transducers are conditioned and fed to a PC/XT using an A/D card. The base parameters or the reference parameters for the control system are softwarecontrolled. Desired diesel replacement can be set for given ranges of load and frequency. The software in the computer processes the data, records and provides instructions to the control system for corrective action during the run. The following are the logical statements.

Read diesel flow rates, voltage, current and frequency and compute load.

Look up table for diesel flow rate in diesel mode at the corresponding load.

Check for the diesel replacement range for the load.

If it is lower, reduce air flow.

If it is higher or the same, then stop.

Repeat step 1 onwards.

The signal obtained from step 4 is processed through the control system to a three-phase geared-motor operating a butterfly valve. The valve is actuated by pulses generated from the control system using relays and timer circuits. Each pulse rotates the valve by approximately five degrees. Thus, for a given load, the position of the valve varies for different diesel replacements. There is also a facility to record the position of the valve in terms of percentage valve opening. For any input signal to the computer a time delay is provided before any corrective action is processed, to account for the system response.

During any load throw-off, the frequency increases; thus the corrective action is to immediately reduce the rpm. If it is not corrected, then explosions in the engine exhaust become inevitable. Thus an additional facility is provided, where the air valve is fully opened when the computer senses frequency beyond the acceptable range. In the above operation, a manual override is provided to supercede the auto-mode. The computer also acts as a data acquisition system, where all the above data are stored in separate output files. The time of sampling the data is also software-controlled. The system provides screen display of all the parameters during the course of run indicating the actions initiated. 


\section{The economic analysis}

\subsection{The economics of gasifiers}

For any technology to be economically viable, the designer should take care to reduce the capital cost of equipment and the operating cost to an acceptable value. The present technology has been developed taking into consideration the above criterion.

In this section, the technique of life-cycle costing is used for the economic analysis and the diesel mode and dual-fuel mode operations are compared. The conventional modes of power generation have been compared with technologies based on renewable sources of energy by Reddy et al (1989). They have examined the entire spectrum of power generation technologies, taking into consideration even the preparation time. From their analysis, the decentralised mode of power generation seems to have a significant edge over conventional technologies. In the present calculations, the gestation period is considered negligible (less than 6 months), since the system is mostly made of prefabricated items and site preparation time is minimal.

Apart from the reliability of the set-up, the question of the system paying back the extra cost incurred over the conventional diesel genset is also very essential. Payback period is determined by computing the extra cost incurred and the savings generated by the use of the new technology.

The total cost for operating a system includes the investment and the running costs. The investment cost or the initial cost in setting up the plant has two components hardware or equipment cost and building cost.

The basic data on the costs of various elements at the time of writing are indicated in the next section.

\subsection{The analysis}

The various parameters are denoted as in table 1 . The values indicated are nominal and are based on actuals in most cases.

The analysis proceeds by obtaining the fixed cost, operating cost $/ \mathrm{kWh}$, and the total cost $/ \mathrm{kWh}$ for the diesel mode and the dual-fuel mode, respectively. The total cost per year is the sum of fixed and operating costs. In the present analysis, the total life of the project is referred to the life of the building. The total cost per year is the sum of fixed and operating costs. Thus the replacement of the elements during the total life considered is based on the individual component life. The present values are computed for all the costs involved during the life cycle, with discount rates of 6 and $12 \%$.

3.2a Cost of maintenance: The maintenance cost for the diesel genset on both diesel and dual-fuel mode is the same except for an additional cost on lubrication oil in the latter where it is recommended to change the lubrication oil once in every $250 \mathrm{~h}$ of operation as against $500 \mathrm{~h}$ in the diesel mode in the $3.5 \mathrm{~kW}$ system, and 100 and $200 \mathrm{~h}$, respectively, in the $100 \mathrm{~kW}$ system. The maintenance costs considered for various components of the system are given in table 2 . Zerbin (1984) indicates a range of $3-6 \%$ of the total cost for maintenance, depending on the number of hours of operation. 
Table 1. The cost parameters for 4.4 and $96 \mathrm{~kW}$ systems.

\begin{tabular}{llcc}
\hline$P$ & Rated power (kW) & $3 \cdot 5$ & 80 \\
$N$ & Number of hours per year & 2500 & 5000 \\
$R$ & Diesel replacement \% & 70 & 70 \\
$C_{e g}$ & Cost of engine-genset (Rs) & 35,000 & $3,00,000$ \\
$C_{w}$ & Cost of wood (Rs/kg) & $0 \cdot 10$ & $0 \cdot 25$ \\
$C_{l u b}$ & Cost of lubricating oil (Rs/litre) & $60 \cdot 0$ & $60 \cdot 0$ \\
$C_{d}$ & Cost of diesel (Rs/litre) & $5 \cdot 0$ & $5 \cdot 0$ \\
$C_{b e}$ & Cost of building (diesel mode) (Rs) & 10,000 & 30,000 \\
$C_{b g}$ & Cost of building (dual-fuel mode) (Rs) & 15,000 & $1,00,000$ \\
$C_{g}$ & Cost of reactor (Rs) & 3,000 & 20,000 \\
$C_{k}$ & Cost of cooling, cleaning & 4,500 & $1,50,000$ \\
& and control system, if any (Rs) & & $2,00,000$ \\
$L_{d g, r}$ & Life of engine-genset, reactor (h) & 25,000 & 25,000 \\
$L_{c c, b}$ & Life of cooling-cleaning system, & 10,40 & 10,40 \\
& building (years) & $12 / 6$ & $12 / 6$ \\
$I_{d g}$ & Interest rate on all elements (\%) & 10 & 10 \\
$S$ & Salvage value (\%) & 10 & 10 \\
$m_{d g}$ & Maintenance of diesel-genset $(\%)$ & 5 & 5 \\
$m_{g s}$ & Maintenance of gasifier system $(\%)$ & 5 & 5 \\
$m_{b}$ & Maintenance of building (\%) & 280 & 280 \\
sfic & Specific fuel consumption, diesel & & \\
& (average) (g/kWh) & $1 \cdot 36$ & $1 \cdot 36$ \\
slc & Specific lubricating oil consumption $(\mathrm{g} / \mathrm{Wh})$ & 5 & 16 \\
$T_{c}$ & Lubricating oil tank capacity (litres) & $1 \cdot 3$ & 10 \\
$s w c$ & Specific wood consumption (kg/kWh) & 2 & 10 \\
$L C_{d g}$ & Labour cost in diesel mode (Rs/h) & 4 & 10 \\
$L C_{g s}$ & Labour cost in dual-fuel mode (Rs/h) & & \\
\hline & & & \\
\hline
\end{tabular}

3.2b Operator costs: Experience with the gasifier engine-genset system reveals that one skilled person and one semi-skilled helper are enough to operate the engine in the dual-fuel mode. Since the operational costs are not enhanced for dual-fuel operation there is no impact on the relative economics. However, any increased operator cost implies that the cost of power will increase. In the case of the $4.4 \mathrm{~kW}$ system, two operators are considered.

At Chattam Island, wood waste is available at $\mathrm{Rs} .0 \cdot 05 / \mathrm{kg}$ from the saw mill. Considering transportation (about $300 \mathrm{~m}$ ) and chipping costs, the total works out to Rs. $0 \cdot 25 / \mathrm{kg}$ of woodchips. The field experience with the gasifier engine-genset system reveals that operating the engine in the dual-fuel mode needs no more than one skilled person with two semi-skilled helpers.

Pay-back period (PBP): Pay-back period = additional investment on the gasifier system/(number of hours of operation $\times$ savings $/ \mathrm{kWh}$ ). In order to do the calculations for a range of parameters a computer program was generated. A sample set of results for the 100 and the $4.4 \mathrm{~kW}$ systems, respectively, are briefly presented in table 2 .

An examination of table 2 shows that while the use of the gasifier-based system raises the fixed costs significantly, the reduction in operating costs due to reduction in the use of diesel more than offsets the rise in fixed cost and thus provides the key for economic operation. The cost of installation is the total cost of all the items, including the building, calculated for unit operating power and it compares favourably with the values quoted for coal-based thermal power generation systems. The 
Table 2. Economics in diesel and dual-fuel mode at $6 \%$ interest rate*.

\begin{tabular}{lll}
\hline Rated capacity (kW) & $4 \cdot 4$ & 96 \\
\hline Load (kW) & $3 \cdot 5$ & 80 \\
& $(3 \cdot 5)$ & $(80)$ \\
Life of the plant (years) & 40 & 40 \\
& $(40)$ & $(40)$ \\
Capital cost (Rs/kW) engine-genset + & 10852 & 4000 \\
reactor & $(10000)$ & $(3750)$ \\
Present value of replacement of & 11330 & 10287 \\
engine-genset + reactor (Rs) & $(10443)$ & $(4644)$ \\
Capital cost (Rs/kW) & 1286 & 4375 \\
cooling, cleaning and control system & $(0)$ & $(0)$ \\
Present value of replacement of cooling, & 1342 & 4560 \\
cleaning and control system & $(0)$ & $(0)$ \\
Total capital cost (Rs/kW) & 28234 & 23382 \\
& $(23300)$ & $(13770)$ \\
Life-cycle fuel cost (Rs/kW) & 27472 & 63712 \\
& $(68782)$ & $(137564)$ \\
Life-cycle operating and maintenance & $3037 \cdot 7$ & 945 \\
cost (Rs/kW) & $(1879)$ & $(744 \cdot 4)$ \\
Fixed cost (Rs/kWh) & $0 \cdot 660$ & $0 \cdot 3810$ \\
& $(0 \cdot 51)$ & $(0 \cdot 165)$ \\
Operating cost (Rs/kWh) & $2 \cdot 56$ & $1 \cdot 09$ \\
& $(3 \cdot 05)$ & $(2 \cdot 10)$ \\
Total cost (Rs $/ \mathrm{kWh)}$ & $3 \cdot 19$ & $1 \cdot 47$ \\
& $(3 \cdot 55)$ & $(2 \cdot 27)$ \\
\hline
\end{tabular}

*Figures in parentheses denote the engine run on diesel alone.

interesting point is that the economy of scales normally expected in MW class power stations seems to be obtained even at these power levels.

Figure 7 indicates the dependence of the pay-back period on the number of hours of operation per year. It is very clear that the smaller system is not an economical substitute for a diesel engine. But it does not rule out the possibility of using such a technology in case the situation demands it.

Figures 8 and 9 present the result of the economic analysis of the larger system. The parametric dependence on pay-back period is studied. The figures indicate the strong dependence of the pay-back period on the number of operating hours and on the cost of wood chips. It is also clear that an increase in interest rates from 6 to $12 \%$ increases the pay-back period by $20 \%$. From figure 9 , the decrease in the pay-back period with increase in number of hours of operation is very evident. Increasing the hours of opeation/year from 2000 to $6000 \mathrm{~h}$ reduces the pay-back period by a factor of about 5 at $70 \mathrm{~kW}$ load and $6 \%$ interest. With a four-fold increase in the cost of wood from Rs 100 /ton to Rs 400/ton the pay-back period changes from $2 \cdot 1$ to $3 \cdot 7$ years. This range of values is reasonable for commercial application of the technology. In the case of the $4.4 \mathrm{~kW}$ system, the cost per unit of electricity is almost the same both in the diesel and the dual-fuel mode, considering 2500 annual operating hours. It is clear that the operating costs are high in the smaller system, basically because 


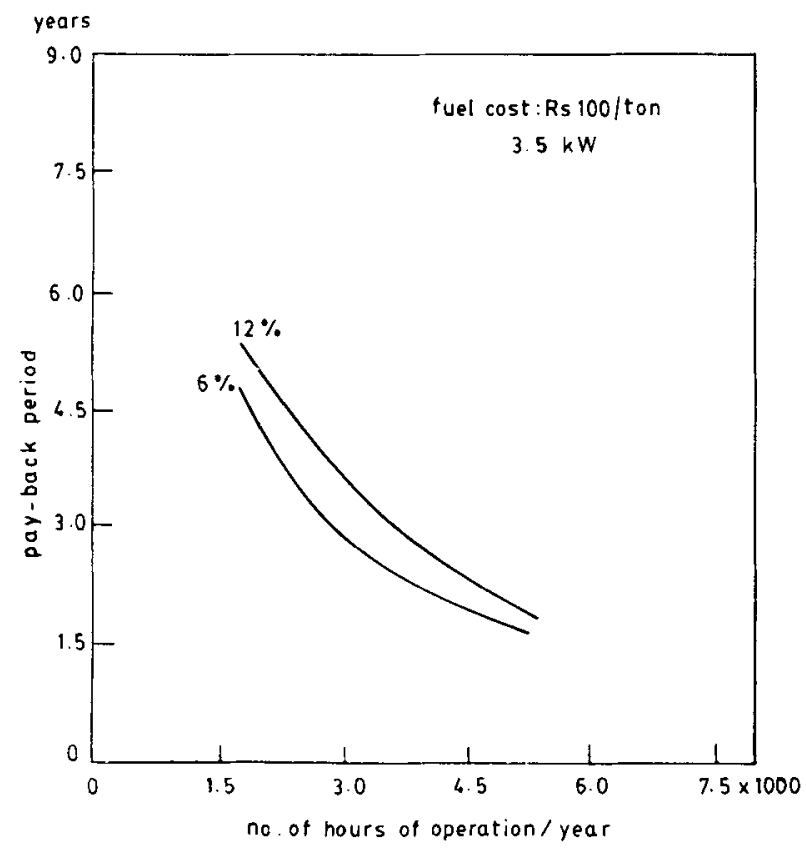

Figure 7. Number of hours of operation vs pay-back period for the $4.4 \mathrm{~kW}$ system.

the labour cost considered here is $\mathrm{Rs} .1 \cdot 14 / \mathrm{kWh}$. With reduction in this cost the cost of electricity would reduce. Even though this is not an attractive proposition, the need for such power packs could occur during fuel crises especially in the agricultural sector where the value addition caused by irrigation is very significant. In Karnataka, users of the $3.7 \mathrm{~kW}$ water pumping system realised the advantage of the gasifier system during the recent oil crisis caused by the Iraq War, during which diesel was rationed. With the increase in the number of hours of operation from 2500 to 5000 hours per year the pay-back period reduces by about $40 \%$. In such situations the economics of the $4.4 \mathrm{~kW}$ system improves and tends towards that of the large system.

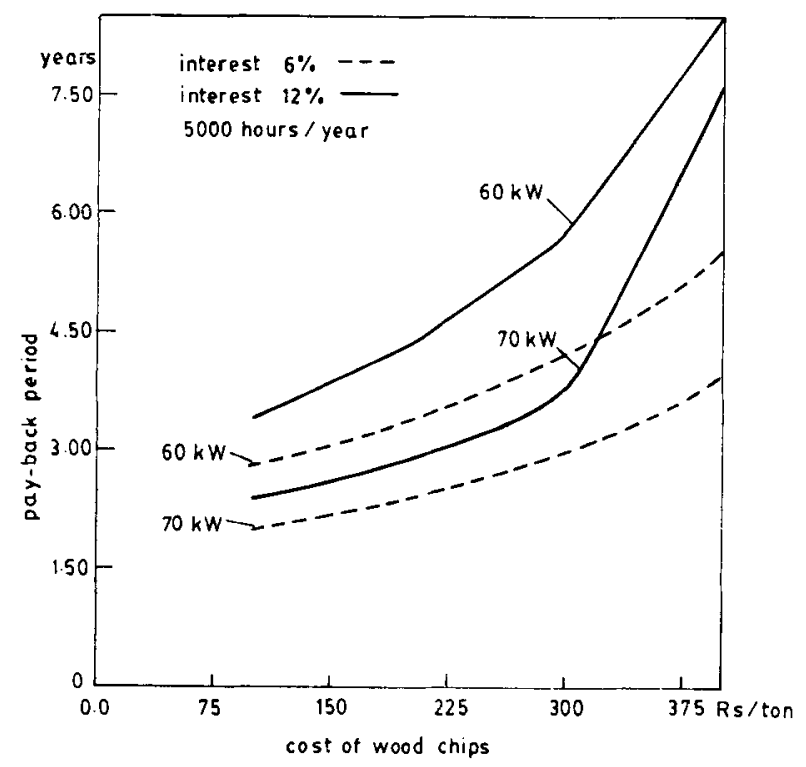

Figure 8. Pay-back period vs cost of woodchips. 


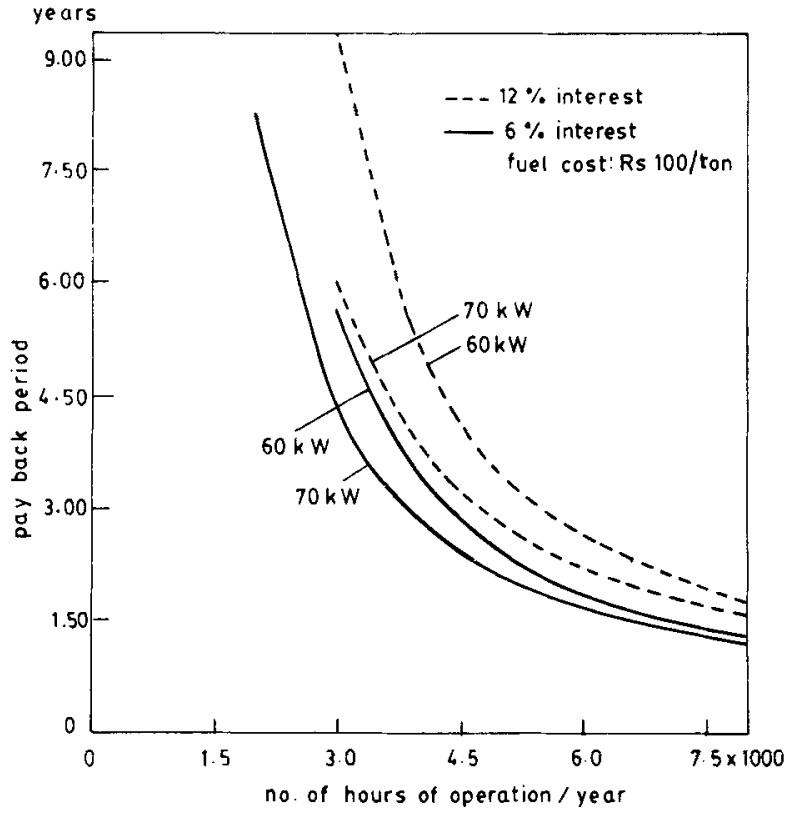

Figure 9. Pay-back period vs number of hours of operation for loads of 60 and $70 \mathrm{~kW}$.

The results presented above on the cost of energy are very typical. One can infer from them that the cost of energy with dual-fuel operation is substantially lower than that with diesel alone. The cost of energy provided by the state is about Rs. $1 \cdot 30 / \mathrm{kWh}$ (which is generally subsidised). Thus the cost of energy from the engine-genset in the dual-fuel mode, run for more hours, is about $10 \%$ higher than that charged by the state electricity board. This difference is not significant if it is recognised that the user is independent of the vagaries of the supply from the state particularly when the value addition due to the availability of energy in an industrial operation is substantial as is true with most industrial products.

\section{Final remarks}

The present paper has discussed the scientific, engineering and economic aspects of gasifier-based energy sources. Some of the possible applications of this technique are water-pumping and electricity-generation systems at various power levels. The use of a gasifier as a heat source is not discussed here as it is much simpler to meet these demands as compared to power generation. This is primarily because the quality of the gas in terms of tar and dust content is much less stringent in heat applications. Further, it is simpler to meet the water-pumping application as compared to electricpower demand because the problems of load following are not complex. It is possible to run a water-pumping system even without a diesel governer in the engine. It must also be brought out that electric supply to an industry with $25-35 \%$ load variation can be handled by a diesel engine in a dual-fuel mode with no difficulty if the engine has an " $\mathrm{A}$ " class governer. The current range of gasifier designs is upto $100 \mathrm{~kW}$. But the present authors see no particular difficulty in designing an efficient gasifier for megawatt power levels. The issue in these cases is really not one of design but of the biomass sources being available without degrading the environment. 
Economic considerations show that at power levels of about and more than $100 \mathrm{~kW}$ the investment into gasifier-based power generation systems will be a commercially attractive proposition. Besides there are many other beneficial aspects not considered in the above study. For instance, a large number of users, plantations and industries, do have diesel-engine pumps or electricity-generation systems in this country since the grid power supply is not adequately reliable. In these cases, the investment is reduced to the gasifier system and auxiliaries. Pay back is ensured within an year for the larger power system. Other developmental efforts to reduce the cost of the reactor by using ceramic shells are being currently attempted.

The results presented here are the outcome of projects on gasifiers, administered and financed partly by the Karnataka State Council for Science and Technology, Bangalore, and by the Department of Non-Conventional Energy Sources, New Delhi. The authors are grateful to them for the support provided.

\section{Appendix A. Development of the first prototype}

While designing the first prototype, the system components were limited to the bare minimum like the reactor and an integral cooling-cleaning system. It was essential at this juncture to develop a reactor geometry for gasification at large capacities.

The reactor was a set of two 3-metre long concentric cylinders of 0.35 and $0.45 \mathrm{~m}$ diameter as shown in figure A1. The outer cylinder was insulated with aluminosilicate blankets. The bottom of the reactor had a cap with an asbestos O-ring. Six nozzles of $19 \mathrm{~mm}$ diameter were used for air supply to the combustion zone. A hot cyclone designed for an inlet velocity of $12-15 \mathrm{~m} / \mathrm{s}$ was used as the dust-removal system. A radiant cooler of $2.8 \mathrm{~m}^{2}$ area and a spray tower constituted the cooling and cleaning system. Both the coolers had a common water-seal at the bottom. The gases from the first radiant cooler were led to the second after making the gas skim over the surface of a stagnant water pool. Figure A2 shows the schematic of the complete system.

\section{Performance in the blower mode}

The system was tested in the blower mode with the following measurements being made: (a) temperatures at the reduction zone, gasifier outlet, cyclone outlet, cooler outlet; (b) static pressure at gasifier outlet, cooler outlet; (c) gas flow rate; (d) wood consumption rate; and (e) gas calorific value.

Starting the system

The gasifier start-up procedure is similar to that of a small-scale system. With an initial bed of charcoal, wood chips of specific size are loaded (moisture content $20 \%$ ). After ensuring the flow of water in the cooling system, the gasifier is connected to the blower suction. A burning wick in line with the air nozzle ignites the char bed and in about $180 \mathrm{~s}$, an ignitable gas is obtained. However, the system is run on the burner mode for about $15-20 \mathrm{~min}$ at reasonably low gas flow rate $(25 \mathrm{~g} / \mathrm{s})$ so that a 


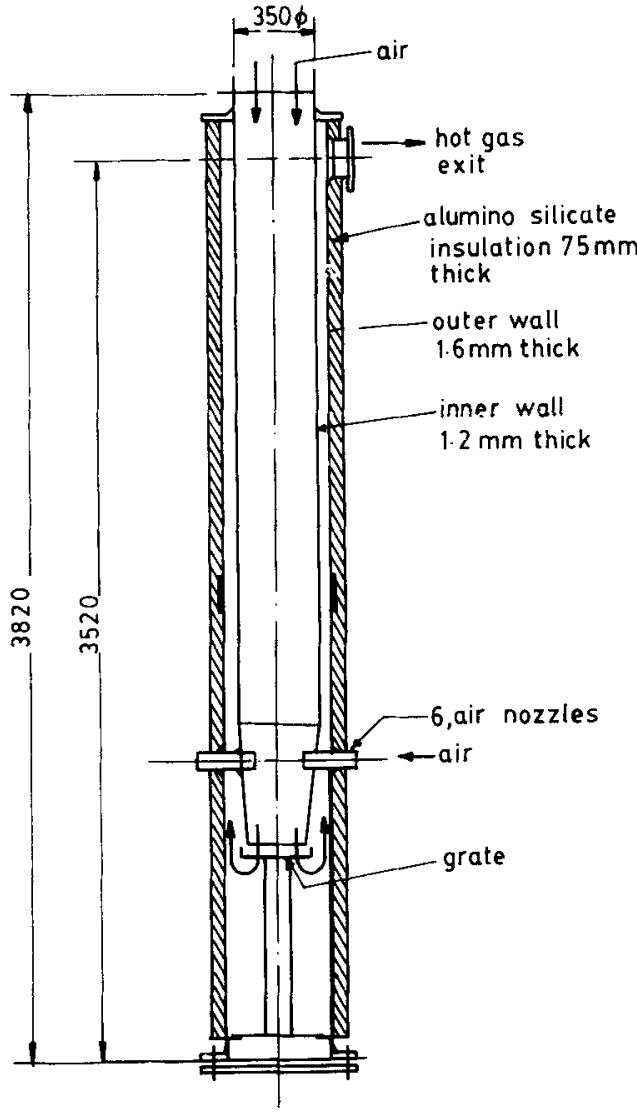

Figure A1. Reactor for the $100 \mathrm{~kW}$ gasifier system (earlier version).

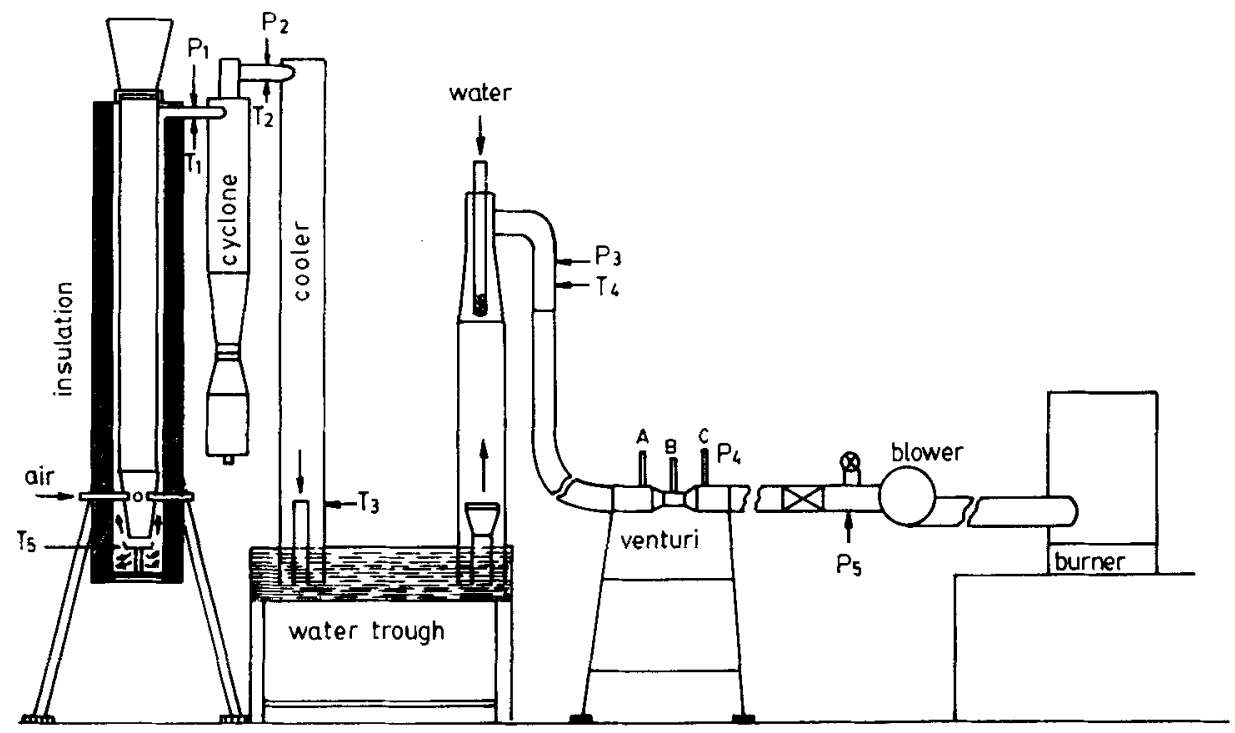

gasifier

Figure A2. System arrangement for gasifier tests. 
thermal profile is established inside the reactor. This is to eliminate the possibility of any unpyrolysed wood chips reaching the reduction zone.

The above procedure is simple and more practical than the one adopted by Walawender et al (1985, pp. 911-22) where start-up is a two-hour operation using a propane burner for initial heating of the reactor, followed by a gradual build-up of the bed.

The size of the wood chips, the combustion zone volume and the air nozzle area were varied to achieve consistent gas quality at varying flow rates. The effect of wood chip size on the gasification was observed at the two extreme limits. With large pieces such as waste from a packaging industry $(50 \times 50 \times 12 \mathrm{~mm}$ to $75 \times 75 \times 12 \mathrm{~mm})$ the following observations were made.

- Material movement was a problem; one had to force the charge from the top to make it move.

- Wood could be seen at the air nozzle, implying that it was not completely charring above the air nozzle region.

- Gas flow rate was never constant and gas quality was poor.

The above problems were related to the bed movement and also the channelling of gases in the bed. In order to improve the charring process, the combustion zone volume was increased, with not much improvement. Increasing the air nozzle area also resulted in poor quality gas. On reduction in the size of wood chips to about $20 \times 75 \mathrm{~mm}$, the gas quality was consistent and the gas flow rate steady. Further size reduction increased the pressure drop across the bed to unacceptable levels.

Though the cyclone was performing satisfactorily in terms of dust collection and cooling of the gas by radiating heat to the ambient, thus reducing the cooler load, the cooling and cleaning system was redesigned by eliminating the hot cyclone. The radiant cooler was converted into a water scrubber. To save on the pressure drop across the cyclone a cold cyclone was used.

The reduction zone temperature reaches around $973 \mathrm{~K}$ in about $10 \mathrm{~min}$ from the start. This is a clear indication that during this period charcoal gasification is taking place and hence the gas produced is devoid of any tar. But it is essential to run the system for about $15 \mathrm{~min}$ to ensure that enough char is generated by the pyrolysis of wood chips.

After the above fine tuning, the gasifier had the following performance.

Gas generation rate

Pressure drop across the gasifier

Typical gas calorific value

Typical gas composition (\%)
$: 80 \mathrm{~g} / \mathrm{s}$ with a $0.75 \mathrm{~kW}$ blower

$: 1300 \mathrm{~Pa}$ at $80 \mathrm{~g} / \mathrm{s}$

$: 1123 \mathrm{~K}$

: $5 \mathrm{MJ} / \mathrm{kg}$

$: \mathrm{CO}_{2}-10-12$

$\mathrm{CO}-18-20$

$\mathrm{H}_{2}-15-18$

$\mathrm{CH}_{4}-1-2$

$\mathrm{N}_{2}-47-50$

While development of various elements, including the auxiliaries, was being carried out, the need for such a system arose in Port Blair due to which this work received a further fillip. The subsequent modifications made in the system to meet the site requirements are detailed in the main text. 


\section{References}

Dasappa S, Shrinivasa U, Baliga B N, Mukunda H S 1989 Five-kilowatt wood gasifier technology: Evolution and field experience. Sädhanā 14: 187-212

Jain B C 1987 Technoeconomics of renewable energy power generating systems. J. Biomass 11: $97-133$

Kardona 1988 The potential of biomass gasifier generator sets as an alternative power plant for rural electrification in Indonesia. Presented at the International conference on Energy from Biomass and Wastes XII, Louisiana, New Orleans

Mukunda H S, Shrinivasa U, Dasappa S, Reddy V 1986 The economics of gasifier systems, Karnataka State Council for Science and Technology Report

Rajan N K S, Colin Crasta, Vikram Krishnan 1990 Data acquisition and Control System for Gasifier-Based Diesel Generation Unit, Report Dept. Aerospace Eng., Indian Institute of Science, Bangalore

Ravindranath N H, Dutta Prasad H L, Mukunda H S 1989 Proceedings of the First National Meet on Biomass Gasification, Indian Institute of Technology, Bombay

Reddy A K N, Sumithra G D, Balachandra P, D'Sa A 1989 The comparative costs of energy conservation and generation from decentralized and centralized sources, Report of the Department of Management Studies, Indian Institute of Science, Bangalore

SERI 1979 Generator gas - the Swedish experience from 1939-1945, Solar Energy Research Institute Report

Taylor C F, Taylor E S 1961 The internal combustion engine (Pennsylvania: Int. Text Book Co.)

Walawender W P, Chern S M, Fan L T 1985 Wood chip gasification in a commercial downdraft gasifier. In Fundamentals of thermochemical biomass conversion (New York: Elsevier Applied Science)

Zerbin W O 1984 Generating electricity from biomass with Imbert gasifier. Thermochemical processing of biomass (London: Butterworths) 